International Journal of Advanced Biological and Biomedical Research Available online at http:www.ijabbr.com

Volume 8, Issue 4 (2020) pp. 339-357

DOI: 10.33945/SAMI/IJABBR.2020.4.2

Original Article

\title{
Finite Element Analysis of Small-scale Head of Combine Harvester for Harvesting Fine-Grain Products
}

\author{
Pourya Bazyar ${ }^{*}$, Ali Jafari ${ }^{1}$, Reza Alimardani1 ${ }^{1}$, Valiollah Mohammadi², \\ James Grichar ${ }^{3}$ \\ ${ }^{1}$ Department of Agricultural Machinery Engineering, Faculty of Agricultural Engineering \\ and Technology, University of Tehran, Karaj, Iran \\ ${ }^{2}$ Department of Agronomy and Plant Breeding, College of Agriculture, University of \\ Tehran, Karaj, Iran \\ ${ }^{3}$ Texas A\&M AgriLife Research, Department of Soil and Crop Sciences, USA, Corpus \\ Christi, TX \\ *Corresponding Author E-mail:pourya.bazyar@ut.ac.ir
}

Received: 11 February 2020, Revised: 28 March 2020, Accepted: 3 April 2020

\begin{abstract}
Brasicanapus L. is one of the most important crops in the world, but every year during mechanized harvesting with conventional combines, large quantities of the seeds fall to the ground and thus result in a decrease in yield. Therefore, designing and manufacturing a head specific for harvesting this crop is a high priority. In this study, the head of a combine for harvesting fine-grained products was designed, manufactured and evaluated. Initially, different designs were modeled in Solidworks 2018 software and analyzed with Ansys workbench 2019 software. The best scheme was selected between different designs and a prototype was developed. The results of the analysis indicated that the fabricated apparatus has sufficient strength and stability while the results of field tests indicate that the generalization of the proposed scheme on the scale of a real combine harvester can help to decrease the grain loss for fine-grained products.
\end{abstract}

Key words: Header, Design and manufacturing, Finite element, Fine-grained products

\section{Introduction}

The worldwide population growth and increasing demand in recent decades for food production have given greater attention to agriculture and related sciences than in the past; therefore, plants with high nutritional value are of particular importance (Lajevardi, 1980). Canola (Brasica napus L.) is a plant of the Brassicaceae family and one of the most important oilseed crops in the world. Its main advantage, besides its high oil content, is that it can be grown in different climates around the world (Langham, 2007). Canola is the third in the supply of vegetable oil after soybean (Glycine max L.) and palm (Elaeis spp.) oil. Canola accounts for about 33\% of vegetable oil production in Iran (Mohamadianet al., 2012) The 
canola plant contains 40 to $42 \%$ protein while the meal contains 38 to $42 \%$ protein, which can be used as feed for breeding animals and fish (Bphillips and Khachatourians, 2001). The most difficult step in growing canola is the harvesting stage, which distinguishes it from crops such as soybeans and wheat (Triticum aestivum L.), because of its special morphological characteristics. When canola is ready to harvest, the pods are very fragile and environmental factors such as wind, hail, rain, etc, can cause the pods to shatter (Hobson and Bruce, 2002) When canola reaches maturity, the thin sheaths of the pod (Siliqua) are highly susceptible to separation at the junction lines and friction between these sheaths can separate these thin layers and increases crop losses (Meakin and Roberts, 1990). Grain loss in winter rapeseed crops can be 11 to $25 \%$. Ideally, grain loss during harvest should be about 2 to $5 \%$ (Hobson and Bruce, 2002).

There are different methods of harvesting grain products depending on the type of pods for each crop including direct harvesting and post-harvesting or sequencing of the two methods (Domeika et al., 2008). Reaping and rowing of a crop are about 5 to $10 \%$ more time consuming than the direct method (Price et al., 1996). Since grain combine harvesters are used for the harvest of crops such as canola, it is necessary to consider variables that are appropriate according to the morphology of this plant and its grain size. For example, the rate of harvesting plays an important role in the rate of seed loss. Research shows that increasing speeds from 4.5 to $6.5 \mathrm{~km} / \mathrm{h}$ result in double loss during separation (Neale, 2001). In a study by (Mirasi et al.,2014) on the amount of wheat loss during harvest using two types of combine harvesters, they concluded that about 34\% of crop losses were related to the combine head (Mirasi et al., 2014). Also, (Masdari et al., 2008; Rahimi and Khosravani 2003) reported grain losses of 47 to $61 \%$ depending on the type of combine headers used (Masdari et al., 2008; Rahimi and Khosravani, 2003).

Accordingly, there has been a great deal of research around the world to develop specific headers and harvesters for various crops. (Ghahraei et al., 2008) investigated the possibility of making a special header for sorghum [Sorghum bicolor (L.) Moench] harvesting. The cutting section of this header had a rotating disc of $53 \mathrm{~cm}$ in diameter and 4 cutting blades and the results showed that a cutting surface, with a $30^{\circ}$ cutting angle, was smooth and non-fractured and cut smoother and more cleanly than the $45^{\circ}$ angle (Ghahraei et al., 2008). In another study, (Zhang, 2015) explored the feasibility of building a machine for harvesting large-scale grain crops. The result of this research was the construction of a timber-front mower with a chassis section fitted with reciprocating blades at the front end that completely separated the granular products in the crushing unit (Zhang, 2015). The research of $(\mathrm{Wu}, 2015)$ aimed to construct a single-saw cutter for harvesting fine-grain crops that had two movable sheets at the top and bottom of the machine and a fixed electric saw at the front end.

In recent years, to increase the efficiency of harvesting canola, vertical cutting combs have been added to headers. This difference in headers caused the grain to be completely separated from the harvested material during vertical cropping, thus preventing the loss of a large amount of grain. Due to the high cost of manufacturing this type of machine and the high cost of importing it into Iran, there is a strong need to internalize these headers. This is especially important for grain crops because the harvest losses in this plant species are far greater than those of other species. It is also important to note that the percentage of grain loss during harvest in Iran is very high due to adverse weather conditions, cultivars grown, and the type of combine harvester used. Therefore, the internalization of this system required by the country's farmers, while preventing the foreign currency from leaving the country, will also is of great value for 
the self-sufficiency and independence of the Iranian agricultural community. Thus far little research has been done on special headers for canola harvest in the country. For example, in a study conducted to investigate canola grain losses during harvesting with three types of combine headers (commonly used, Iranian-made header, and Austrian-made header), results showed that the common type had the highest and the Austrian type the least grain loss during harvest (Mohamadian, 2012).

Given the above, the purpose of this study was to develop a special cost-cutting header for the harvesting of fine grain products such as canola to reduce grain loss during harvest and increased the amount of harvested products.

\section{Materials and methods}

\section{Review of some basic designs}

Different systems were investigated for harvesting fine-grained products. In the first design (Figure 1A) a u-shaped finger was proposed, which had a cutting section consisting of a reaper and a helix to transfer the cut stems into the tank. In the second design (Figure 1B), a u-shaped finger system with straps and feeding rollers was used. In this design, a suction fan with a grid entry compartment as well as a stem transfer hub for seeded crops, along with a double return knife, was used to cut the stem. In the third design (Figure 1C), bowl fingers, stair frame, a reel, a stem-collecting tank, and a cutter were used for cutting. In the fourth design (Figure 1D), a sloping triangular bowl overlap mechanism, a stepped chassis, a stem collecting tank, highaltitude separators on the sides and a cutter were used to cut the crop. According to the weighting table, each of the designs was evaluated with predetermined criteria (Table 1).



(A)

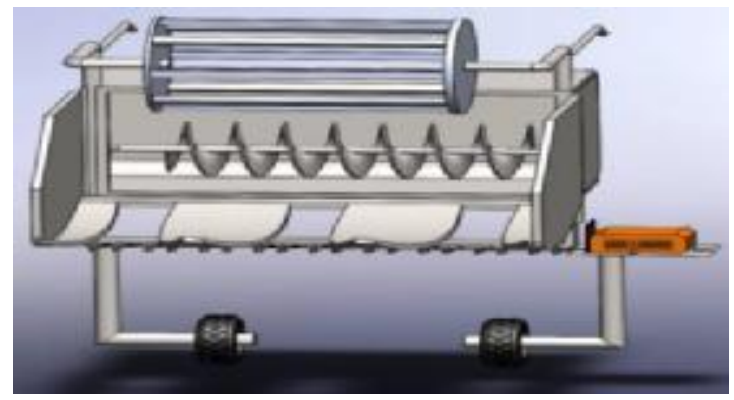

(C)

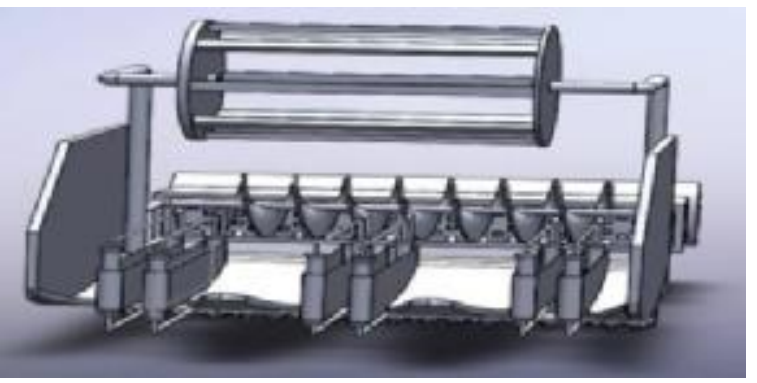

(B)

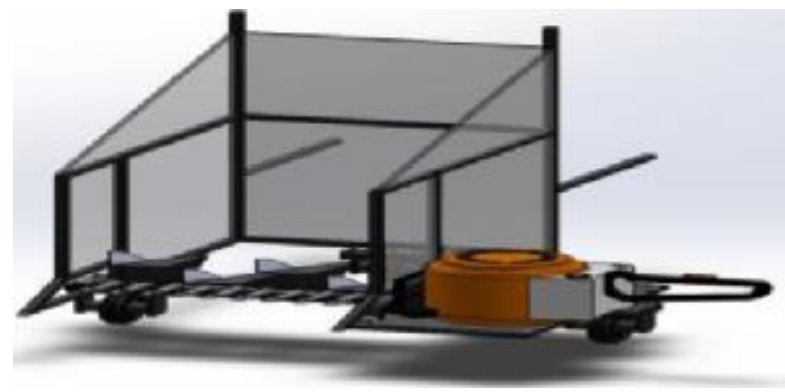

(D)

Figure 1.

The advantages and disadvantages of designs A, B, C, and D to reduce the grain loss in seed products were studied. Design D was selected as the best design (Amir Fazli, 2001), 
because this design had lower energy consumption in contrast to others and also had lower construction costs, thus making it economically feasible for farmers (Bazyar et al., 2019).

Table 1. A comparison of refined creative designs of the different combine heads

\begin{tabular}{|c|c|c|c|c|c|}
\hline \multicolumn{3}{|c|}{ Refined Creative Designs } & \multirow{2}{*}{$\begin{array}{l}\text { Criteria } \\
\text { Weight }\end{array}$} & \multirow{2}{*}{ Criteria } & \multirow{2}{*}{ Standard Number } \\
\hline $\mathbf{C}$ & $\mathbf{B}$ & $\mathbf{A}$ & & & \\
\hline - & - & - & 6 & Energy consumption & 1 \\
\hline - & - & - & 1 & Easy to maintain & 2 \\
\hline- & - & - & 2 & Weight of the machine & 3 \\
\hline- & - & - & 7 & $\begin{array}{l}\text { Authenticity } \\
\text { low number of pieces }\end{array}$ & 4 \\
\hline- & - & - & 8 & Cost of production & 5 \\
\hline- & - & - & 3 & $\begin{array}{l}\text { Convenience of } \\
\text { shipping }\end{array}$ & 6 \\
\hline- & + & + & 5 & $\begin{array}{l}\text { Failure to loss to either } \\
\text { side }\end{array}$ & 7 \\
\hline- & + & - & 4 & $\begin{array}{l}\text { Transfer grain to } \\
\text { reservoir }\end{array}$ & 8 \\
\hline $\begin{array}{l}(-) 36 \\
(+) 0 \\
(-) 36\end{array}$ & $\begin{array}{l}(-) 27 \\
(+) 9 \\
(-) 18\end{array}$ & $\begin{array}{l}(-) 31 \\
(+) 5 \\
(-) 26\end{array}$ & \multicolumn{2}{|c|}{$\begin{array}{l}\text { Negative point } \\
\text { Positive point } \\
\text { Total point }\end{array}$} & \\
\hline
\end{tabular}

\section{The head of combine design}

The design of the machine was based on the reduction of grain loss. It should be noted that this machine needs manpower to move and advance. The main parts of the machine include the collection tank, product cutting unit, separator unit with high elevation and nylon coverage, and the stair frame system (Figure 2). The bowls with the overlap between them first make the stem of the cereal crop pass through these fingers (Figure 3). The stem is then bent and directed to the incision of the head. The presence of long dividers in the head with high-height nylon cover eliminates the possibility of any grain shedding from the head. Any spillage is also poured into the bowl. Due to the sloping design of these fingers, the grains inside the bowl are directed to the grain collection reservoir.

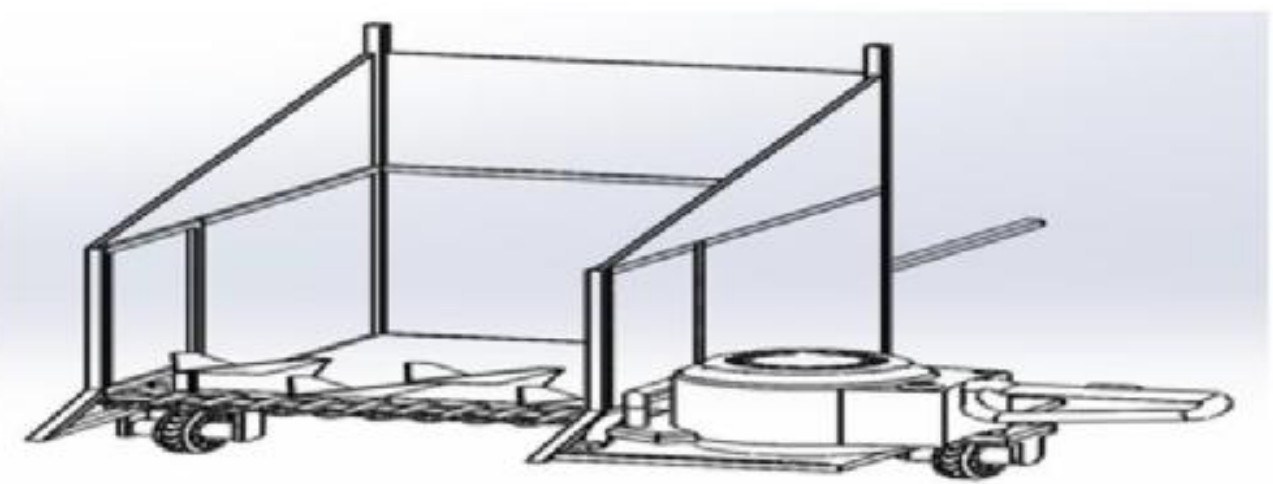

Figure 2. Specific head of combine for harvesting fine-grained products with high head loss 


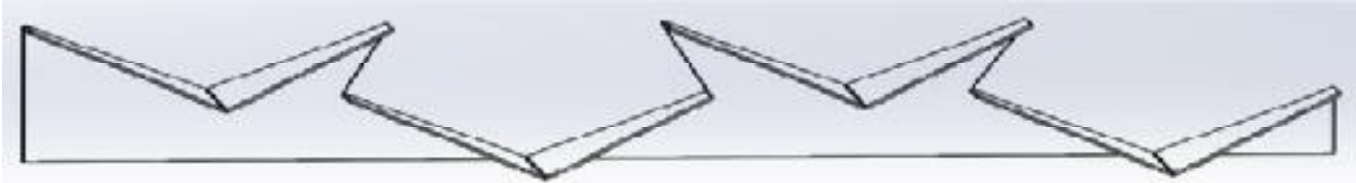

Figure 3. Bowled fingers steep, stair frame

There were two things to consider when designing the reservoir. First, the reservoir should not be large enough that the pressure on the soil will create a hard layer on the soil and secondly that the reservoir should not be smaller than the high-grain cereal such as the crop plant, because this causes the grain to vibrate and be thrown from the sides of the reservoir to the ground and therefore not accurately calculate the amount of grain falling into the reservoir. Therefore, the volume of the reservoir was designed based on the average plant height of the small grain crops and the weight loss of the plant for easy transport to the field. According to the analysis of the device in Solidworks 2018 software, the machine weight is approximately $38 \mathrm{~kg}$ and the reservoir volume is calculated, designed and built equal to 0.24 cubic meters.

The cutting unit plays a key role in determining the width of the work and must be inexpensive, lightweight and accessible to farmers and occupy limited space. Therefore, the most common type of cutting machine used in the country-side was selected by farmers. Since double comb blades consist of fixed blades for cutting and removable blades for combine inertia and holder for cutting the product, combine blades with small scale need cutting machines. It had a small cutting width and was similar to the reciprocating knife system. A German-made Stihl saw bellows machine with a power of $1.1 \mathrm{hp}$ and a weight of $5.4 \mathrm{~kg}$ was used for this purpose.

Since the total mass of the machine " $\mathrm{m}$ " is obtained from the sum of the mass of the machine " $m_{h}$ " and the mass of the gutter " $m_{h t}$ ", to move the machine in the worst terrain conditions $\left(30^{\circ}\right.$ slope) need a 639 Newton gravitational power according to 1 Equation.

$$
\mathrm{g}=9.81 \mathrm{~N} \cdot \mathrm{m} / \mathrm{s}, \mathrm{F}=\left(\mathrm{m}_{\mathrm{h}}+\mathrm{m}_{\mathrm{ht}}\right) \times \mathrm{g}+\left(\mathrm{m}_{\mathrm{h}}+\mathrm{m}_{\mathrm{ht}}\right) \sin \alpha
$$

Also, the required forward speed to move at a speed of $0.2 \mathrm{~m} / \mathrm{s}$. According to Equation 2, its tensile strength will be 128 watts.

$$
\mathrm{P}=(\mathrm{F}+\mathrm{mg} \sin \alpha) \times \mathrm{V}
$$

The power required to cut the stem of the plant was obtained by Equation 3, where $\mathrm{P}_{\text {cut }}(\mathrm{kW})$, $\mathrm{F}_{\mathrm{xmax}}$ (maximum cutting force in $\mathrm{KN}$ ), $\mathrm{X}_{\mathrm{bu}}$ (stem thickness at start of blade contact in $\mathrm{mm}$ ), $\mathrm{f}_{\text {cut }}$ (number of cuts per number per minute), $\mathrm{C}_{\mathrm{F}}$ (The ratio of the average force to the maximum force) (Behrouzi Lar et al., 2006).

$$
P_{c u t}=\frac{C_{F} \cdot F_{x \max } \cdot X_{b u} \cdot f_{c u t}}{6 \times 10^{4}}(\text { Eq. 3) }
$$

Other features of the head of combine designed in this study are also presented in Table 2.

Table 2. Technical specifications of the head

\begin{tabular}{cccc}
\hline Amount & Item & Amount & Item \\
\hline $20 \times 20$ & The blade dimensions $(\mathrm{cm})$ & 60 & Device width $(\mathrm{cm})$ \\
$2 \times 2$ & Size of the can $(\mathrm{cm})$ & 38 & Device weight $(\mathrm{kg})$ \\
2 & Thickness of the cards $(\mathrm{cm})$ & 0.04 & Device volume $\left(\mathrm{m}^{3}\right)$ \\
108 & angle between pitch (degrees) & $\mathrm{X}=0.65, \mathrm{Y}=0.75, \mathrm{Z}=1.02$ & Center of gravity $(\mathrm{m})$ \\
\hline
\end{tabular}


The presence of ontologies in the cape along with nylon cover (Figure 4) separates part of the crop for reaping and the possibility of any seed shedding from the edges of the head of combine and if there is a loss it will be thrown into the bowl blades.



Figure 4. The divider with high height and nylon coverage unit

\section{Types of analysis for small-scale head of combine harvester}

Device simulation analyses were performed using Ansys workbench 2018 software as follows.

\section{Static analysis of bowl fingers with stepped frame}

In the static analysis, it was assumed that this structure had to withstand physical loads. Initially, the structures designed in Solidworks 2018 software have meshed and fixed supports were identified and then loaded. In this analysis, a force of 26 Newton is applied, which is the average force applied by the stem of the fine grain products to these fingers (Khak Rangin et al., 2013). Figure 5 shows finger fixation, fixation of the fixative and the force applied by the stem to the finger.

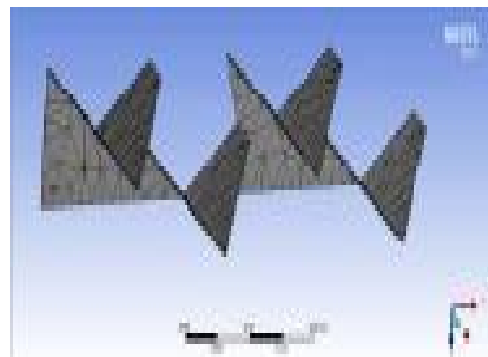

A

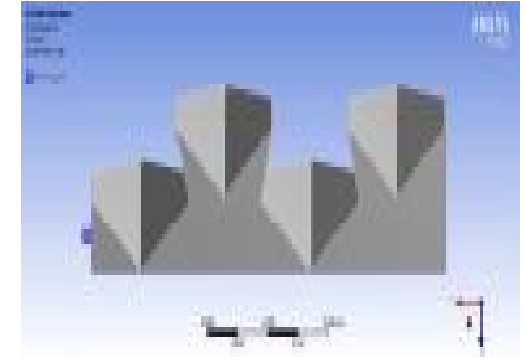

B

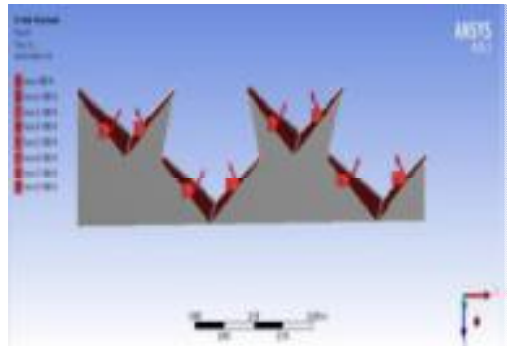

C

Figure 5. The static structure of the bowl fingers: A) Triangular modeling, B) Fixed stand support, C) Determination of forces exerted by the stem

\section{Transient analysis}

The analysis assumes that the machine is moving on a ridge at a height of $0.5 \mathrm{~m}$ (the height of the rails is usually 30 to $40 \mathrm{~cm}$ on agricultural land, which is assumed to be $0.5 \mathrm{~m}$ for greater reliability). The initial speed was zero and secondary velocity was calculated according to Equation 4.

$$
V^{2}-V_{0}^{2}=2 g h
$$


"V2" is the second velocity in $\mathrm{m} / \mathrm{s}, \mathrm{V}_{0}{ }^{2}$ " is first velocity $\mathrm{m} / \mathrm{s}$," $\mathrm{g}$ " the acceleration of gravity and " $\mathrm{h}$ " of the stack height that in this study is assumed to be $0.5 \mathrm{~m}$. After obtaining the secondary velocity, acceleration was calculated with Equation 5 that was $153 \mathrm{~m} / \mathrm{s}^{2}$.

$$
V^{2}-V_{0}^{2}=2 \mathrm{ax}
$$

In this equation, " $x$ " is the value of the depression in the soil and it is equal to 0.03 . In figure 6 , the collapse of the device from a hypothetical height is shown to perform transient analysis. Then, Equation 6 was calculated. The calculated power was $55 \mathrm{~N}$.

$$
V^{2}-V_{0}^{2}=2 \mathrm{ax}
$$

Where "F" is the unifying force of the Newton unit, " $\mathrm{m}$ " is the mass unit, and "a" is the unit acceleration of per square meter.

\section{Cut fatigue analysis}

According to the research carried out by (Khak Rangin et al., 2013) a fatigue analysis of a factor of 100 Newton is inserted into line X, the measure of analysis in this study is the number of fatigue forces (Khak Rangin et al., 2013).

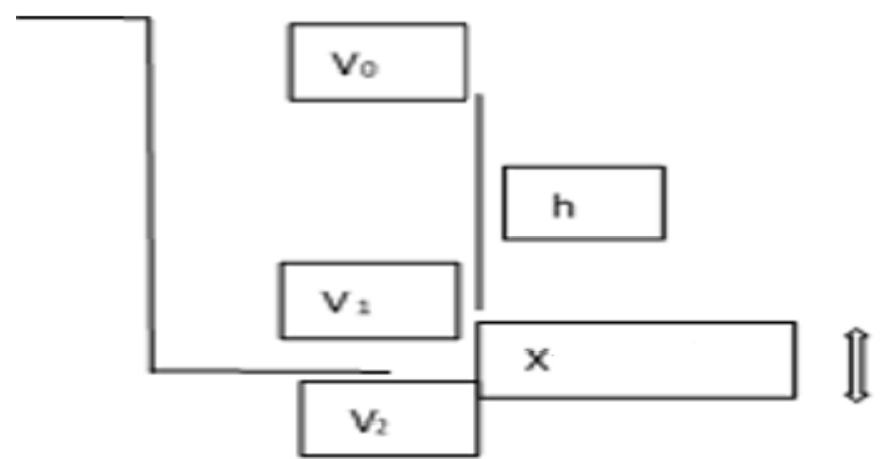

Figure 6. Modeling of the device from a hypothetical height on the farm, to analyze transient loads

\section{Modal analysis}

Modal analysis was tried to extract five natural frequencies. Concerning Equation 7, the motion travels at a maximum velocity " $v$ " on the pile to the distance " $\lambda$ " the frequency of the external load on the bowl is equivalent to the following equation:

$$
f=v / \lambda
$$

In this equation, "f" is the frequency in Hertz, "v" is the speed of motion per meter per second and " $\lambda$ " is the distance of the two stacks per meter. According to Eq.7, with assuming that the machine is moving at a velocity of 1 meter per second on the mounds to the distance $\lambda=20 \mathrm{~cm}$, the frequency of the external load on the device chassis is equal to 5 Hz. Modal analysis was performed and compared with the external load frequency (to avoid the phenomenon of aggravation).

\section{Chassis harmonic analysis}


In this analysis, the reaper of the machine was investigated with the reaper motor having $4000 \mathrm{rpm}$. Figure 7 shows the determination of the forces applied to the harmonic analysis. The direction of force as shown in Figure 7 in red is in the same direction as "x". Its mass was measured using the Solidworks software. The obtained mass was $5.54 \mathrm{~kg}$. Equation 8 is for calculating the motor clamp size.

$$
X=\frac{1}{2} a t^{2}
$$

In this Equation " $\mathrm{X}$ " is the motor speed in $\mathrm{m} / \mathrm{s}$, "a" is acceleration whose unit is $\mathrm{m} / \mathrm{square}$ per second and "t" time in seconds. Then in Equation 9 "F" is the force in kilograms in Newton, " $\mathrm{m}$ " is the mass in units of kg and "a" acceleration in units of meters in squares.

$$
\mathrm{F}=\mathrm{ma}
$$

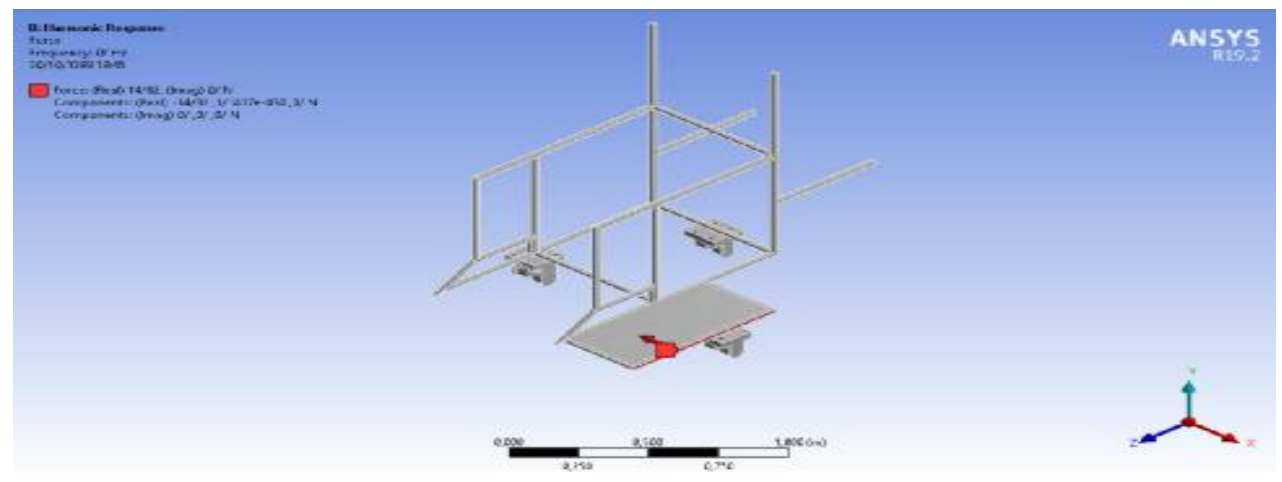

Figure 7.Determination of forces applied in harmonic analysis

\section{Manufacturing the heads of combine}

After modeling and analyzing, the machine was manufactured at the BioSystems Engineering Department of the Faculty of Agriculture, University of Tehran. Iron cans measuring $2 \times 2 \mathrm{~cm}$ were used to make the reservoir. The length and width and height of the reservoir were considered to be $60 \mathrm{~cm}$.

A special chassis is mounted to place the harvester in front of the head of the combine to apply cutting. After reaping the chassis, the reaper was stabilized. To manufacture the inclined bowl fingers and stepped frame, a steel plate with a thickness of $2 \mathrm{~cm}$ was used. To construct a stair frame, first triangular cuts were performed by using a pair of scissors. The height of the triangular cuts is $7 \mathrm{~cm}$ and the sides of each cut are $10 \mathrm{~cm}$ and the angle between them is 104 degrees (Figure 8). At the last stage, the stepped frameof bowl fingers was welded to the front part of the head of combine. 


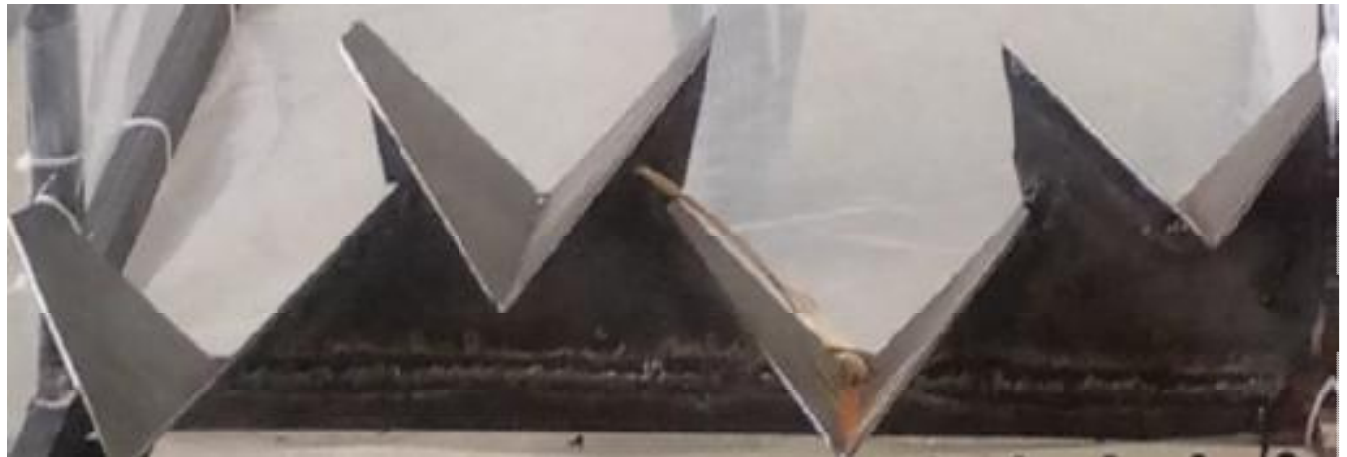

Figure 8.The connection of bowl fingers of a stepped frame to the front part of the head of combine using the welding machine

\section{Results}

\section{Results of static analysis of bowl fingers, with a stepped frame}

According to the simulation results in Ansys software, the properties of this analysis showed that the volume and finger mass of the bowl in the static state were sequentially $3.7607 \mathrm{e}-004$ and $3.9522 \mathrm{~kg}$. Statistical results have indicated that (node 6536) and (element 2999) had the highest displacement and were more likely to have damage in this part. Figures 9-11 show the deformations of the bowl-shaped fingers and the strain and stresses applied to the fingers, sequentially. In Figure 9 the maximum deformation was calculated as $0.0015152 \mathrm{~m}$.
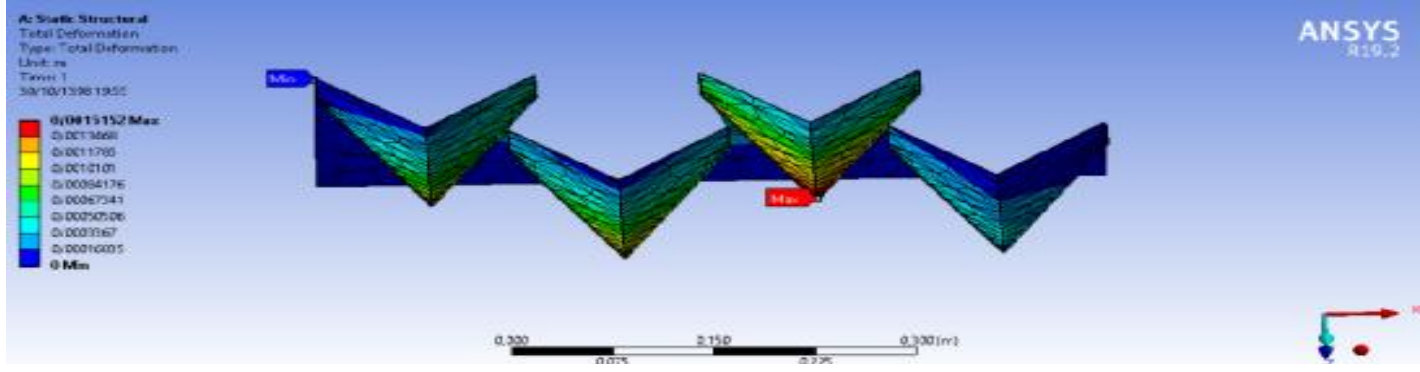

Figure 9. Complete bowl finger deformation

Also, Figure 10 shows the elastic strain of the fingers at the lowest and maximum possibilities were $6.4117 \mathrm{e}-8$ and $0.00071849 \mathrm{~m}$, sequentially.

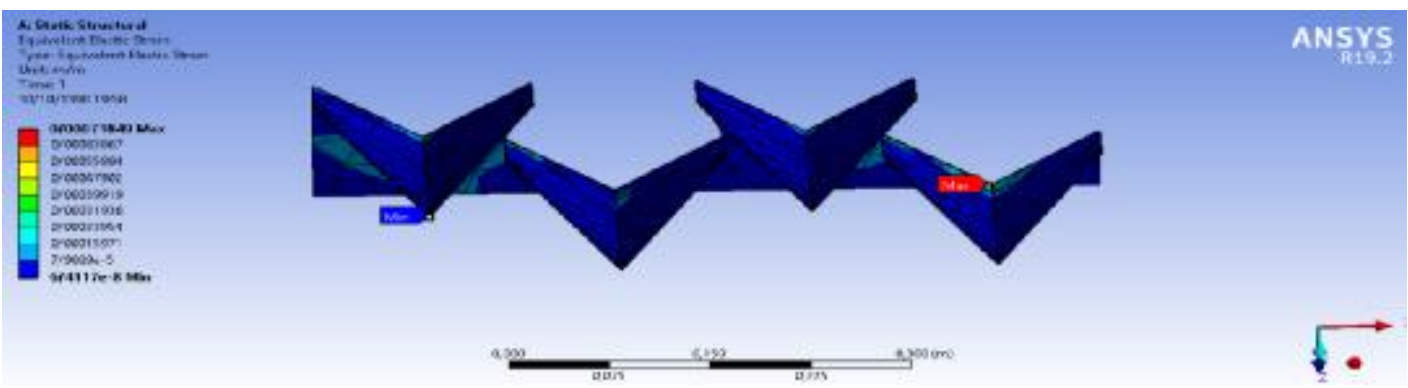

Figure 10. Elastic finger bowl strain 
According to Figure 11, the stresses applied to the manufactured finger at the lowest and maximum possible situations were sequentially 3.4623 and $1.2075 \mathrm{e} 8$ Pascal. The calculated stress is lower than the steel yield stress of $234 \mathrm{MPa}$. In this case, the bowled finger unit with a stepped chassis has sufficient strength against the force exerted by the plant stem.

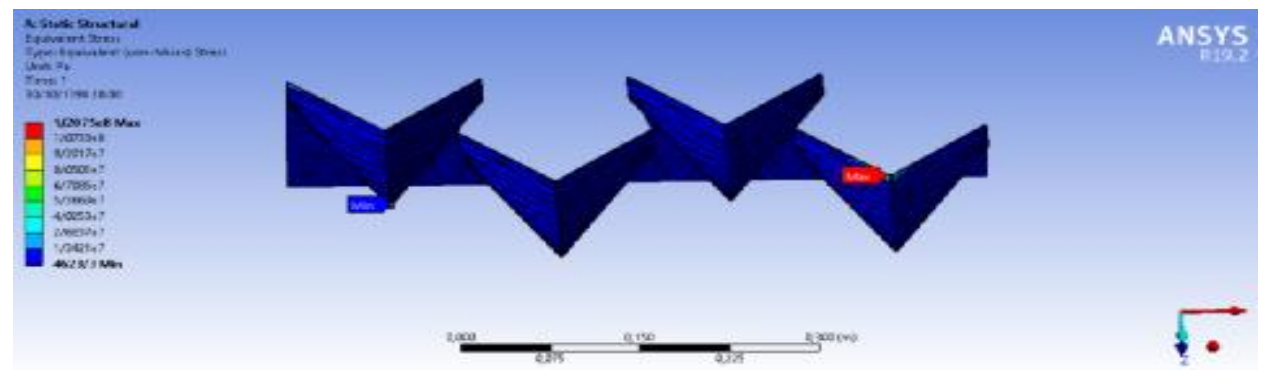

Figure 11. The stress applied to a bowl finger

\section{Results of transient analysis}

This analysis includes dynamic analyses with the effects of inertia and time-varying loading. Figures 12 and 13 show the chassis deformation and stress, respectively. According to these results, the overall deformation in the chassis was 0 in the lowest possibility and the maximum deformation was $0.00012045 \mathrm{~m}$. The results of the stresses applied to the chassis were calculated as the lowest and maximum possible as zero and 4.8617e 6 Pascal, respectively.
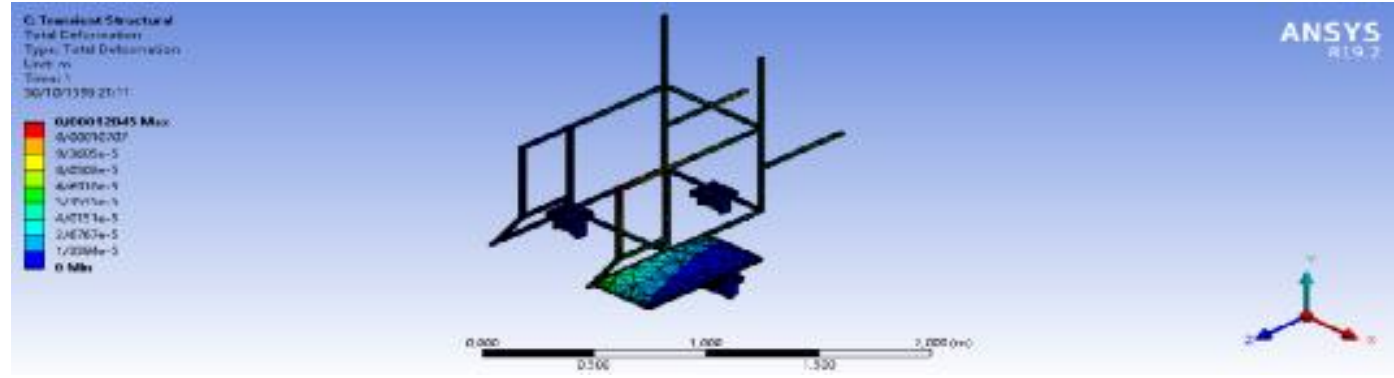

Figre 12. Complete chassis deformation
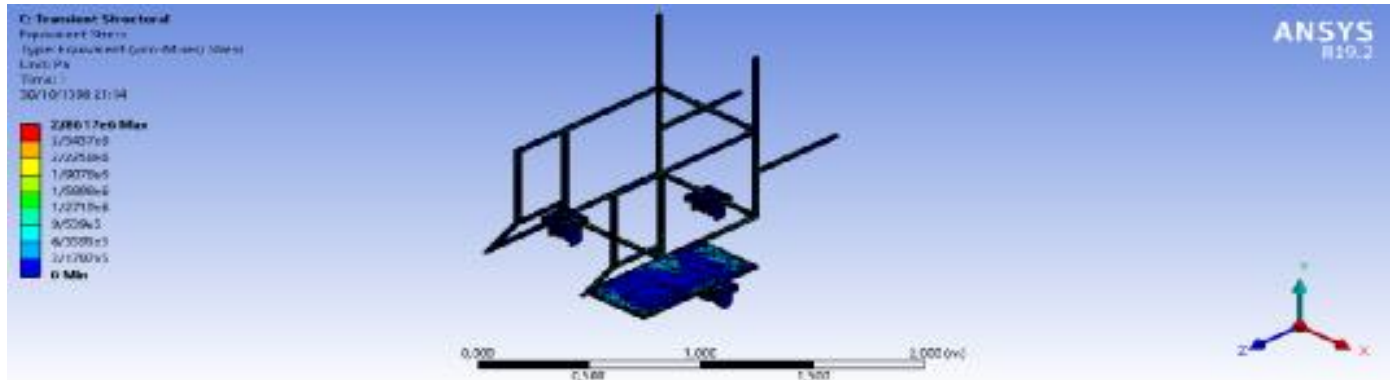

Figure 13. Chassis tension

\section{Results of fatigue analysis of cutting section}

Figures 14-17 sequentially show the deformations, stresses, fatigue life, and cutoff reliability. According to these results of the cutting section of the manufactured machine, 
the highest deformation was $1.0386 \mathrm{e}-6 \mathrm{~m}$ and the lowest deformation was zero. The results for the stress applied to the shear section were obtained at the lowest and maximum amounts of zero and 6.2813e5 Pascale, sequentially. Fatigue life results showed that after one million cycles of fatigue life, the lowest and maximum amount of both were $1 \mathrm{e} 6$. According to the analysis, the results of the coefficient of determination are the lowest and the highest value of 15 and are mechanically high and the probability of fatigue is very low.

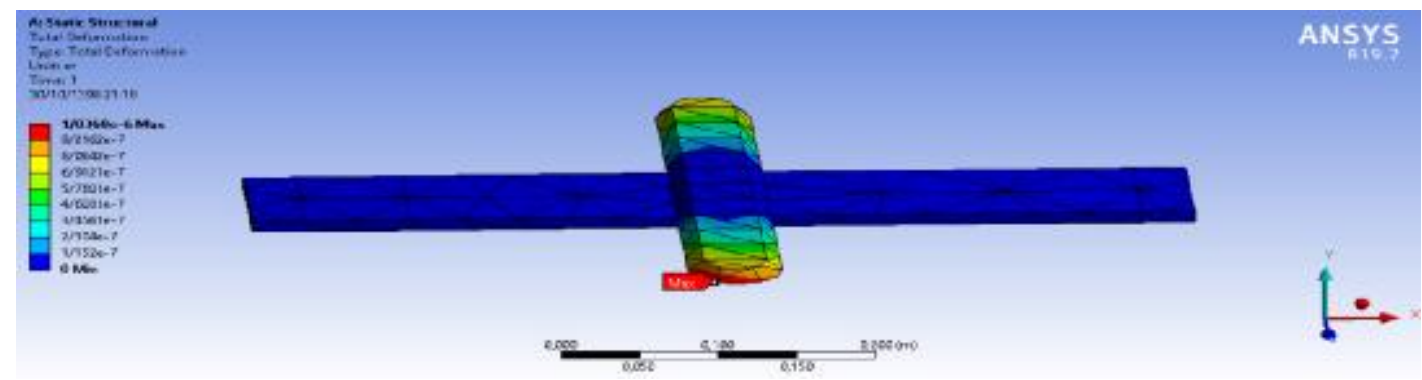

Figure 14. Complete deformation of the cutting section

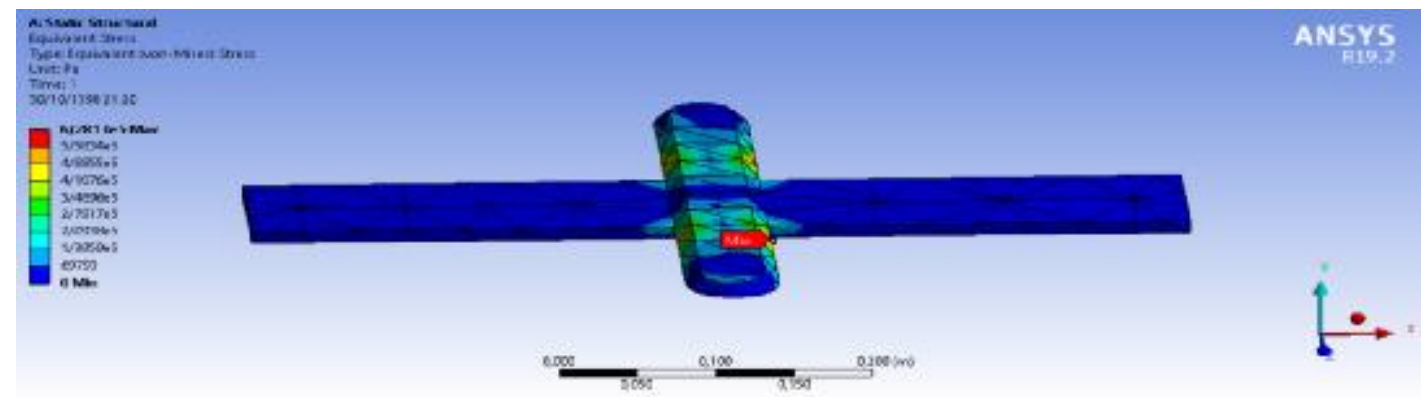

Figure 15. Stress into sections

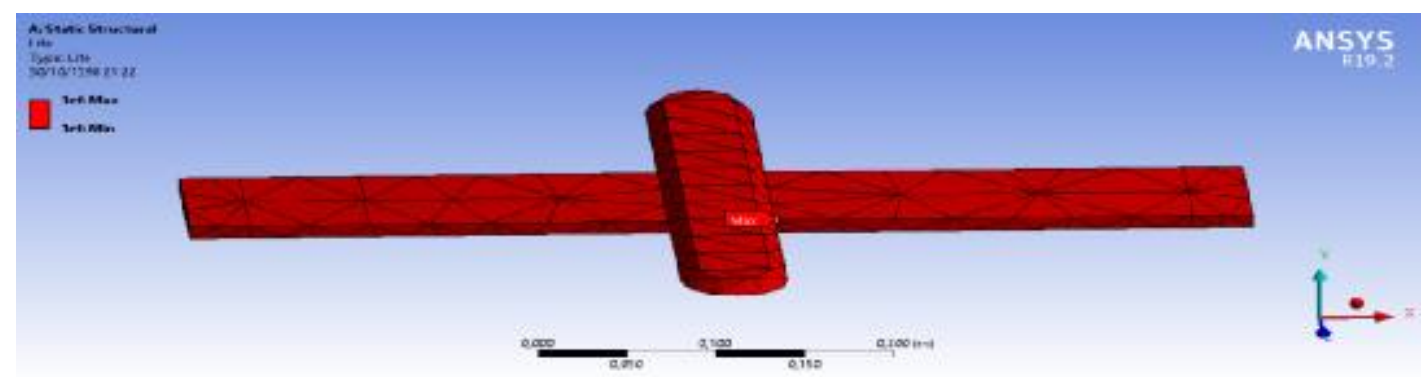

Figure 16. The fatigue life of the cutting section

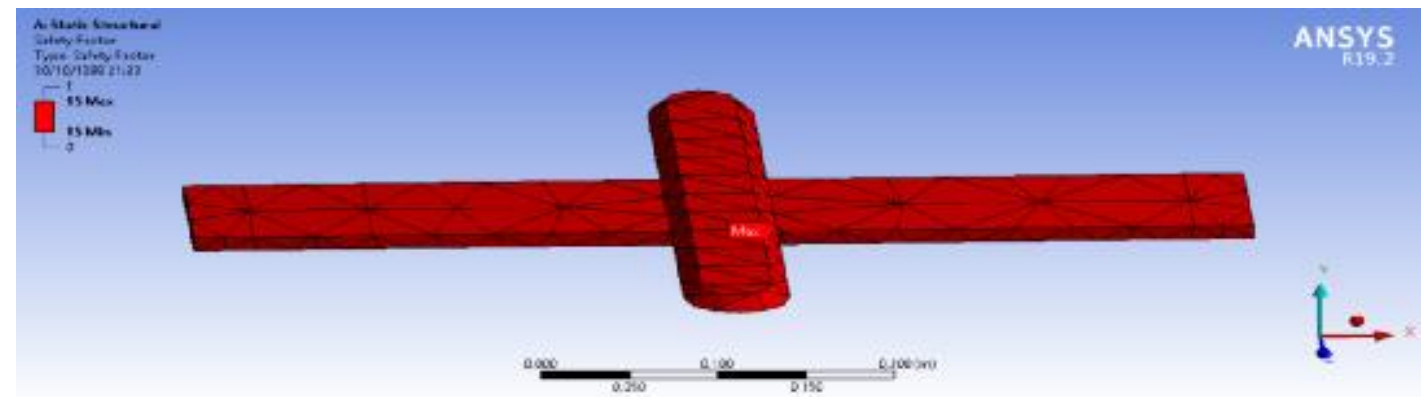


Figure 17. Cutoff reliability coefficient

\section{Results of bowl fingers modal analysis with stair frame}

The results of the blade model were obtained in 15 cases as shown in Table 3 . Mode 15 vibrates at $647 \mathrm{~Hz}$ and Mode 1 at 46/895 $\mathrm{Hz}$.

Table 3. The vibration frequency of a bowl finger with a stepped frame

\begin{tabular}{ll}
\hline Frequency (Hz) & Mode \\
\hline 46.895 & 1 \\
82.512 & 2 \\
108.27 & 3 \\
162.58 & 4 \\
197.06 & 5 \\
\hline
\end{tabular}

The chassis modal deformation in modes 1, 2, 3, 4 and 5, as well as the modal blade elastic strain, is shown in the following figures.

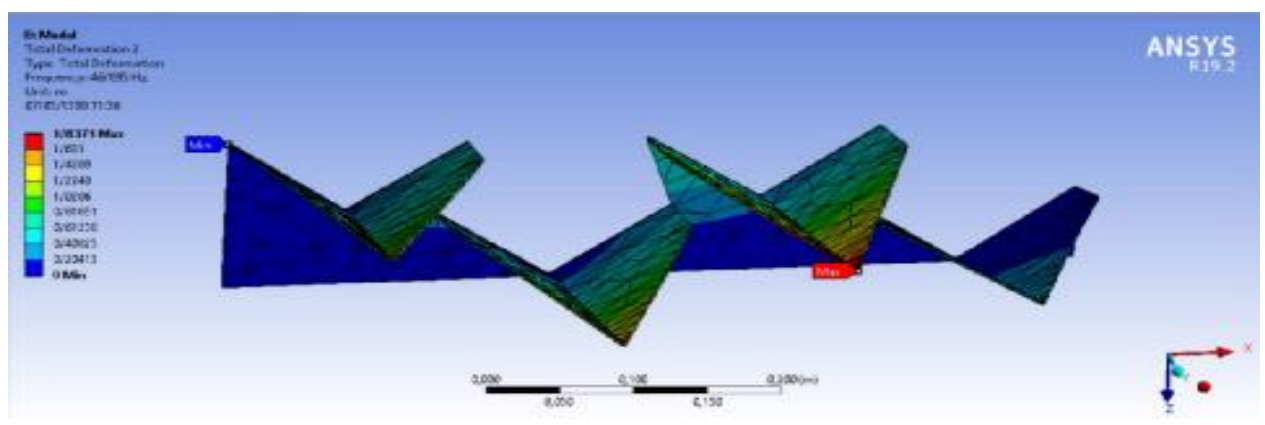

Figure 18. Modal analysis of Bowl finger with stair chassis (mode1)

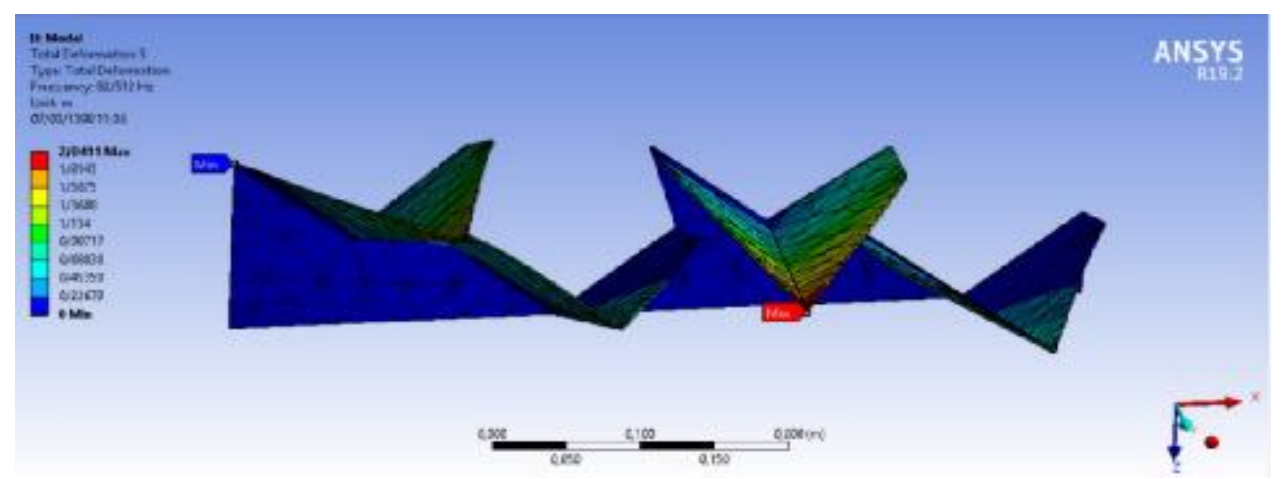

Figure 19. Finger bowl with stair chassis (mode 2) 


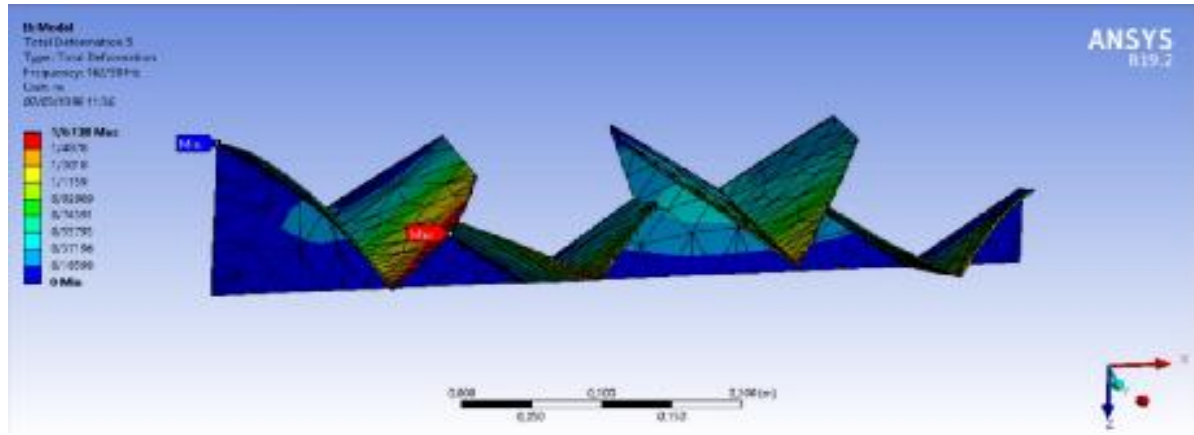

Figure 20. Finger bowl with stair chassis (mode 3)

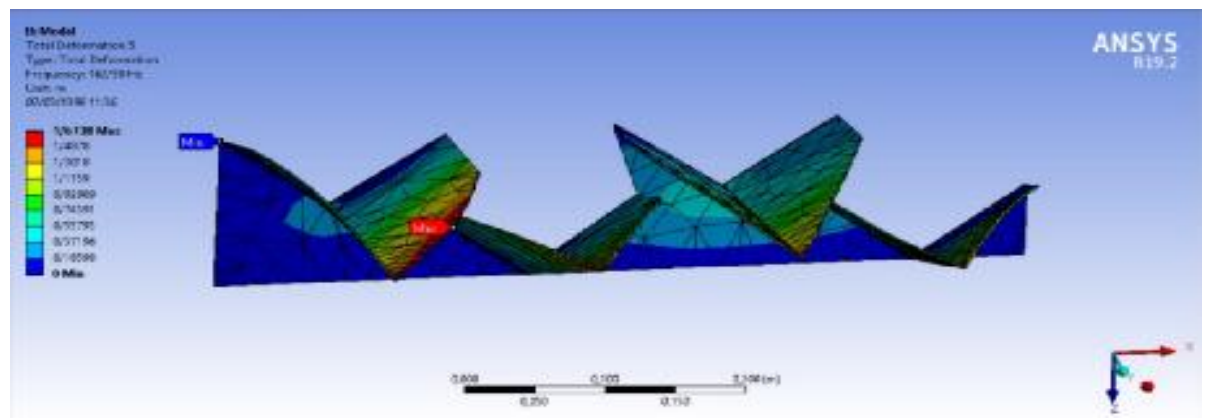

Figure 21. Deformation of bowl fingers by stair chassis (mode 4)

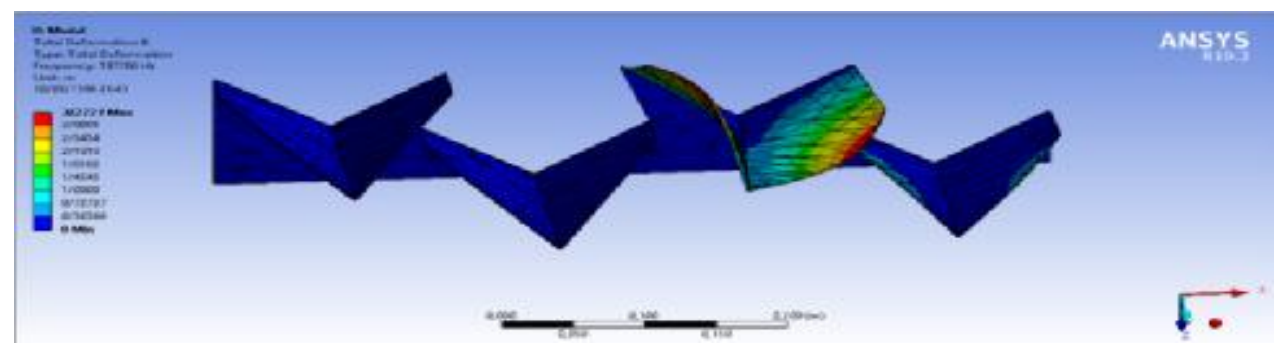

Figure 22. Deformation of bowl fingers by stair chassis (mode 5)

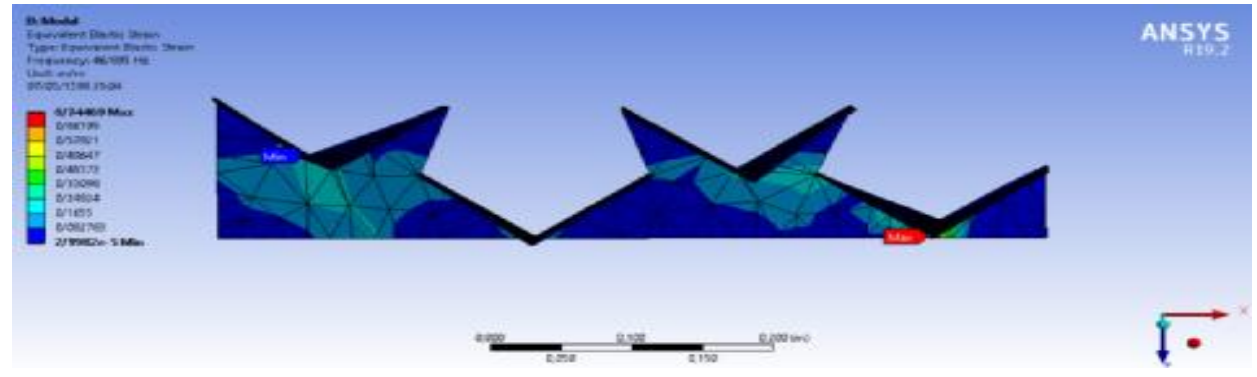

Figure 23. An elastic strain of modal bowl fingers

\section{Modal chassis results}


The results of the chassis modal deformation resulted in 15 states, as shown in Table 4 . Mode 15 was obtained with a frequency of $11.28 \mathrm{~Hz}$ and Mode 1 with a frequency of 23.28 $\mathrm{Hz}$.

Table 4. Chassis vibration frequency

\begin{tabular}{cc}
\hline Frequency (Hz) & Mode \\
\hline 23.168 & 1 \\
34.149 & 2 \\
40.16 & 3 \\
41.393 & 4 \\
48.432 & 5 \\
\hline
\end{tabular}

In this study, as for each case, there is one software output form for modal chassis deformation; so, in fact, there are 15 shapes out of which only 5 shapes are presented in this study. Figures 24-29 show the chassis modal deformation in 1, 2, 3, 4 and 5 modes and modal blade modulus, respectively. According to these analyses, the minimum and maximum deformationat mode 1 (Figure 24) are zero and $0.79129 \mathrm{~m}$ with a frequency of $23.28 \mathrm{~Hz}$, sequentially. Figure 25 shows the lowest deformation in state 2 with a maximum of $0.90578 \mathrm{~m}$ and a frequency of 34.114.

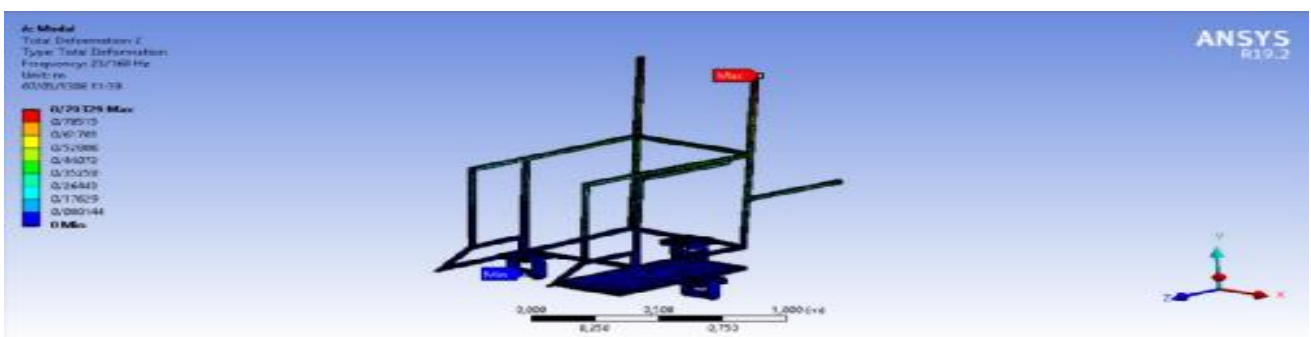

Figure 24. Chassis modal deformation mode 1

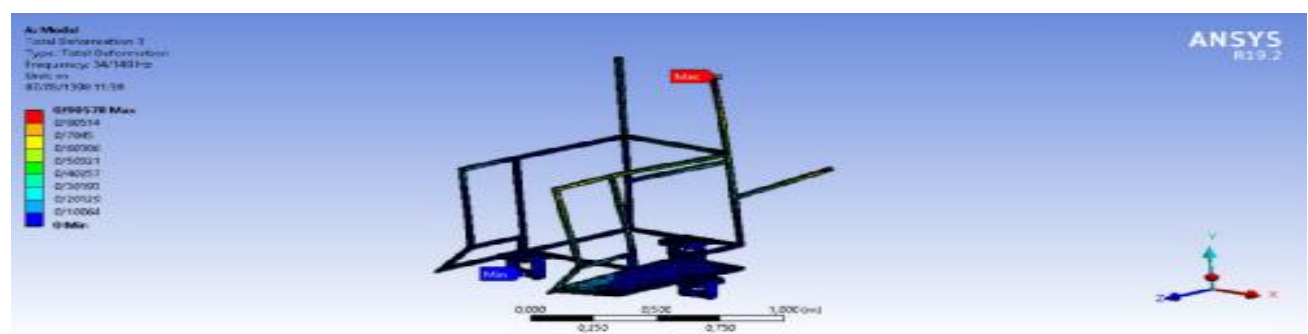

Figure 25. Chassis modal deformation mode 2

In Figure 26 the deformation in state 3 was calculated as the lowest with zero and the highest with $0.91991 \mathrm{~m}$ and frequency of 40.16 . Figure 27 shows the deformation in state 4 calculated as the lowest with zero and the highest with $0.9248 \mathrm{~m}$ with a frequency of 41.393. In Figure 28 Deformation in state 5 was calculated as the lowest with zero and the highest with $1.4383 \mathrm{~m}$ and with a frequency of 48.432. According to the results of the elastic strain in Figure 29, the minimum and maximum changes were calculated as 0/04361 m. Since the external load frequency is lower than the one of the most effective state, it indicates that the device will not be intensified in this state. 


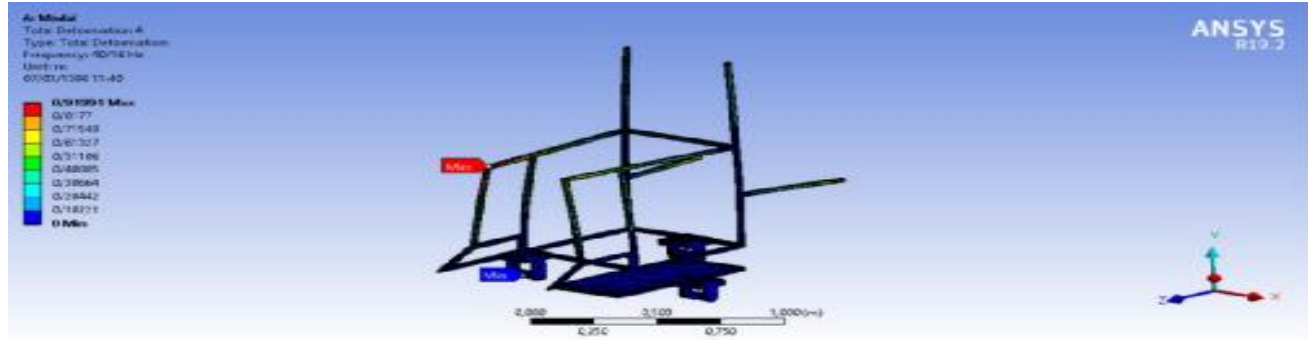

Figure 26. Chassis modal deformation mode 3



Figure 27. Chassis modal deformation mode 4

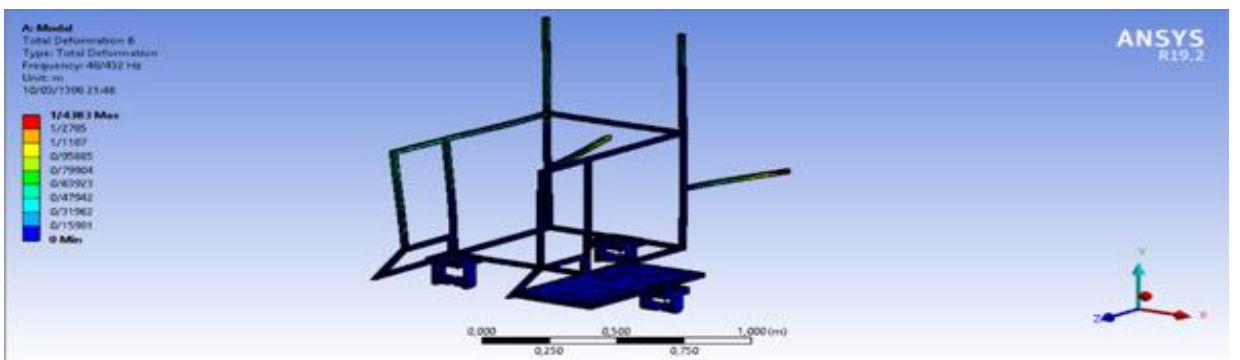

Figure 28. Chassis modal deformation mode 5

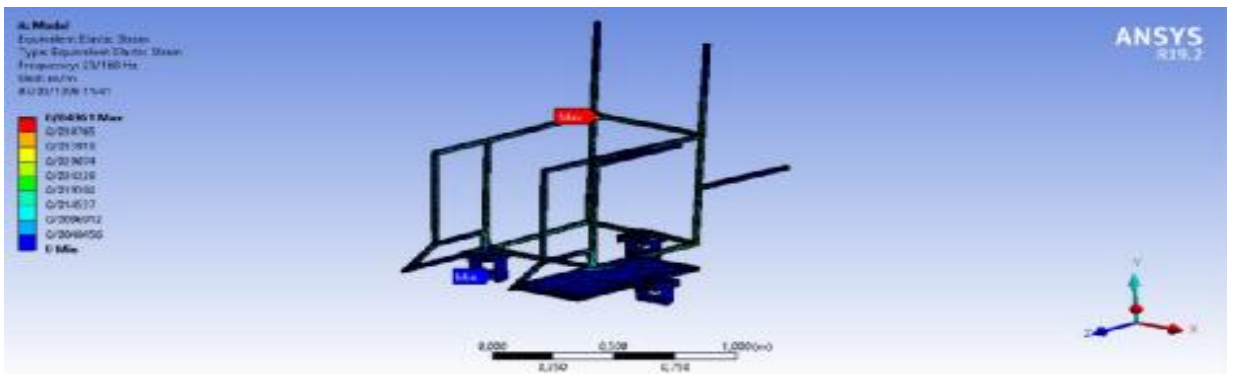

Figure 29. Model elastic strain chassis model

The properties of the chassis modal analysis are shown in Table 5. The chassis volume and mass were 5.5396 e -003 and $43.486 \mathrm{~kg}$, sequentially.

Table 5. Results of linear deformation response frequency

\begin{tabular}{ccc}
\hline Phase (degree) & Range (m) & Frequency (Hz) \\
\hline 180 & $1.1592 \mathrm{e}-008$ & $1.5 \mathrm{e}-003$ \\
180 & $1.1592 \mathrm{e}-008$ & $3 \mathrm{e}-003$
\end{tabular}




\begin{tabular}{ccc}
180 & $1.1592 \mathrm{e}-008$ & $4.5 \mathrm{e}-003$ \\
180 & $1.1592 \mathrm{e}-008$ & $6 \mathrm{e}-003$ \\
180 & $1.1592 \mathrm{e}-008$ & $7.5 \mathrm{e}-003$ \\
180 & $1.1592 \mathrm{e}-008$ & $9 \mathrm{e}-003$ \\
180 & $1.1592 \mathrm{e}-008$ & $1.05 \mathrm{e}-003$ \\
180 & $1.1592 \mathrm{e}-008$ & $1.2 \mathrm{e}-003$ \\
180 & $1.1592 \mathrm{e}-008$ & $1.35 \mathrm{e}-003$ \\
180 & $1.1592 \mathrm{e}-008$ & $1.5 \mathrm{e}-003$ \\
\hline
\end{tabular}

\section{Results of harmonic chassis}

Chassis harmonic deformation is shown in Figure 30. According to the analysis, the deformation with the frequency of $1.5 \mathrm{e}-002 \mathrm{~Hz}$ and the minimum and maximum values obtained for the harmonic deformation of the chassis were 0 and 3/06665e 7.



Figure 30. Harmonic chassis deformation

\section{Discussion}

After investigating the designs and the advantages and disadvantages of various headers, the main objective was to examine the small-scale head of combine harvester against external loads when harvesting fine-grain products. The results reveal that this header has firmness and stability for harvesting fine-grain products. Moreover, canola harvesting with the constructed header showed that the average seed loss in this chamber was $14 \%$ which was lower than that of conventional combines (Izadinia et al., 2005). The device was manufactured on a small scale, which, according to the results of the analysis, can be extended to a large scale and attached to a real combine. As mentioned earlier, the pods of the canola are very fragile at harvest, and its branches are intertwined. When the plant is harvested with conventional combines, grain losses increased. (Srivastava et al., 1993) reported that the combine header losses in canola included crop lodging, natural seed loss, and brush comb loss (Srivastava et al., 1993). Accordingly, when canola is harvested with conventional combines, the pods twist and tear, thereby causing quality reductions and yield loss. The use of a special harvesting header greatly reduces these grain losses and therefore increases crop yield. Vertical reciprocating blades, which are located in fine-grain harvesting heads, can reduce grain loss. The design and construction of these special headers also showed that high efficiency can be achieved with lower costs. In a similar experiment, (Mortezapoor et al., 2009) designed a hydraulic rotary separator using two cylinders with different rotational directions. This machine had a large number of swivel-able fingers inside the cylinders that gently opened the branches and results 
showed that the lowest seed loss was obtained when operated at $75 \mathrm{rpm}$ (Mortezapoor et al., 2009). (Ivancan, 1996) also compared grain losses at harvest time using a grain harvester with a conventional head-harvesting combine and a special head with a longer platform bottom and vertical cutting shoulder. The results showed that the loss of grain in this specific head was 102.6 to $160.3 \mathrm{~kg} / \mathrm{ha}$, while in the normal head the cereal harvest was 269 to $390 \mathrm{~kg} / \mathrm{ha}$ (Ivancan, 1996). In the end, it is suggested that researchers should analyze the various heads of combine harvesters in the world when harvesting various fine-grain products. Also, it is better to examine these heads of combine harvesters in different farms with different kinds of soil and classify different heads of combine harvesters in the world according to the type of crop and soil.

\section{Conclusions}

The world population growth has increased the need for food production and one method to increase crop yield is to reduce crop losses and Theoretical analysis of the various heads of combine harvesters for testing their robustness and stability. It generally reduces the cost of practical tests. Canola is a plant that, due to its complex and fragile pods, can have a great loss of seed during harvest with conventional combines. These studies show that by reducing the twisting and tearing of the pods with this special header, seed quality and yield losses can be prevented. Also, since the optimum moisture for canola harvest is 5 to $6 \%$, the use of an optimum knocker speed is very important to reduce these reductions in quality. The use of a vertical cutting bar also can improve the efficiency of harvesting canola. The results of this study showed that by using available materials obtained at a much lower cost, a special header for harvesting such crops was devised. In comparison to conventional combines, in addition to lower costs, this header can greatly reduce grain losses at harvest time.

\section{Acknowledgments}

I appreciate the help of the manager and authorities at the Department of Agriculture Machinery from the University of Tehran for helping me with the construction of the harvester. Moreover, thanks to the authorities of the farm of the Seed Breeding Research Institute in Karaj, Iran.

\section{References}

Amir Fazli, A. (2001). Design methods in engineering. Publication of Sharif University. First edition. pp. 25-30.

Bazyar, P, Jafari, A, Alimardani, R, Mohammadi, V. (2019). Small-scale head of combine for harvesting sesame. Agricul. Eng., 22(4):02.

Behrouzi Lar, M, Jafari, A, Mobley, H. (2006). Identification and application of cereal combines.Agricul. Bank J., 1:20-30. Link:

Bphillips, PW Khachatourians, GG. (2001). The biotechnology revolution in global agriculture: Invention and investment in the canola sector. CAB Pub., USA. p. 5-15.Link: 
Domeika, R, Algirdas, J, Steponavicius, D, Buktus, V, Vaiciukevičius E. (2008). The estimation methods of oilseed rape harvesting losses. Agron. Res., 6:191-198.

Ghahraei, 0, Khoshtaghaza, MH, Desabin, A. (2008). Design and development of special cutting system for sweet sorghum harvester. J. Central Eur. Agricult., 9(3):469-474.

Hobson, RN, Bruce, DM. (2002). Seed loss when cutting a standing crop of oilseed rape with two types of combine harvester header. Biosystems Eng., 81:281-286.

Ivancan, S. (1996). Problems with the harvesting of rape. Aktual. Mehan., 6:151-155.

Izadinia, Y, Asudar, MA, Shafeinia, AS. (2005). Evaluation of rapeseed mortality in direct harvesting by three types of combine platforms. National Conference on Agricultural Waste Disposal. p. 51-59.

Khak Rangin, R, Shamsi, H, Ranji, A, Pour Ali Ashkalak, M. (2013). Determination of effective agronomic parameters for the design and manufacture of sesame harvest combines. 8th National Congress of Bio systems Engineering and Mechanization, Ferdowsi University of Mashhad, Iran. Page numbers: 7.

Lajevardi, S. (1980). Oilseeds. University of Tehran Publications. No. 1773. p. 50-60.

Langham DR. (2007). Phenology of sesame. In: Janick J, Whipkey A, editors. Issues in New Crops and New Uses. Alexandria, VA. ASHS Press; 2007. p. 144-182.

Masdari, A, Edallat, MH, Khalili, MG, Kalantari, H. (2008). Harvesting wheat losses and anticipated data analysis to model imaginary variables. Papers on Fifth Nati Conf of Agri Machinery Engineering and Mechanization. Ferdowsi University of Mashhad. Mashhad. p 1-7.

Meakin, PJ, Roberts, JA. (1990). Dehiscence of fruit in oilseed rape (Brassica napus). I. Anatomy of pod dehiscence. J. Experimen. Botany., 41:995-1002.

Mirasi, A, Asoodar, MA, Samadi, M, Kamran, E. (2014). The evaluation of wheat losses harvesting in two conventional combine(John Deere 1165, 955) in Iran. Int. J. Adv. Biol. Biomed. Res., 2:1417-1425.

Mohamadian, SA, Mobli, H, Rafie, S, Sadeghnejad, HR, Mohamadi, A. (2012). Compare the amount of Canola losses in harvest time with three types of head. Asian J. Agricult. Sci., $4: 40-42$.

Mortezapoor, H, Raofat, MH, Kamgar, S. (2009). Fabrication and evaluation of hydraulic rotary separator for canola harvesting. Sci. Technol. Agricult. Natural Res., 47:181-193 (In Persian with English abstract).

Neale, T. (2001). Harvesting field crops. Department of primary industries, Queenland, Canada. Volume 1, p. 10-30.

Price, JS, Hobson, RN, Neale, MA, Bruce, DM. (1996). Seed losses in commercial harvesting of oilseed rape. J. Agricult. Eng. Res., 65:183-191. 
Rahimi, HA, Khosravani, A. (2003). Assessment of decreasing wheat losses methods on harvesting stages in Fars province. Papers on First Nati Conf of Assessing Agri Crops Waists. Agri Faculty of Tarbiat Modaress University. Tehran. p 45-51.

Srivastava, AK, Carrol, EG, Rohrbach, RP. (1993). Engineering principal of agricultural machines. ASAE text book, St. Joseph, Michigan: American Society of Agricultural Engineers. p.50-75

Wu, Y. (2015). Single-saw sesame reaping machine (patent). Application number: CN104272920A. p.1-2.

Zhang, D. (2015). Large-scale harvester is used to sesame (patent). Application number: CN204860092U. p.1-2.

How to cite this article: Pourya Bazyar, Ali Jafari, Reza Alimardani, Valiollah Mohammadi, James Grichar, Finite Element Analysis of Small-scale Head of Combine Harvester for Harvesting Fine-Grain Products. International Journal of Advanced Biological and Biomedical Research, 2020, 8(4), 339-357. Link: http://www.ijabbr.com/article 38948.html 